\title{
BIBLIOTECA EM TEMPO REAL: O ACESSO EM FOCO: PROPOSTA CRÍTICA DO MODELO DE ORGANIZAÇÃO DA INFORMAÇÃO NA CONTEMPORANEIDADE
}

\section{Zaira Regina Zafalon}

\section{Resumo:}

O trabalho propõe questionamento e criticidade quanto à adoção de expressões como "biblioteca virtual" ou "biblioteca digital" para conceituar o modelo de organização da informação na contemporaneidade. Contextualiza, histórica e culturalmente, as bibliotecas de modo a apresentar definições, tipologias e amplitude de definições de vários autores. Propõe o reescalonamento das bibliotecas pelo vetor do acesso à informação, haja vista a formação de redes para transferência de informações, a reconfiguração do tempo e do espaço ora vigentes e a forma com que as tecnologias computacionais afetam a criação, o uso, a gestão e o fluxo da informação, de modo a serem abordadas as bibliotecas in loco, em tempo real e híbridas. Propõe-se que, qualquer que seja a unidade documentária a ser disponibilizada, os atuais projetos de construção de bibliotecas em tempo real deverão, inevitavelmente, requerer um processo de revisão dos modelos ultimamente em uso, abarcando, inclusive, as funções dos profissionais envolvidos, a preservação, legibilidade e acessibilidade de documentos digitais por programas específicos.

\section{Palavras-Chave:}

Biblioteca em tempo real, Biblioteca in loco, Biblioteca híbrida, Organização da informação, Cibercultura, Biblioteca virtual, Biblioteca digital.

\section{REAL TIME LIBRARY: FOCUS ON THE ACCESS: CRITICAL PROPOSAL OF THE INFORMATION ORGANIZATION MODEL IN THE CONTEMPORANEITY}

\begin{abstract}
:
The paper proposes questioning and criticality on the adoption of terms such as "virtual library" or "digital library" to conceptualize the model of organizing information in the contemporaneity. It contextualizes, historically and culturally the libraries, in order to provide definitions, types and extent of definitions of several authors. Proposes the rescheduling of libraries through the information access vector, in face of the development of networks for information transfer, the reconfiguration of present time and space, and how the computing technologies affect the creation, use, management and information flow, so as to address libraries "in loco", in real time and hybrid. It is proposed that, whatever the documentary unit to be available, the current projects for constructing real time libraries will, inevitably, require a review process of the recent models in use, covering even the functions of the professionals involved, the preservation, readability and accessibility of digital documents by specific computer programs.
\end{abstract}

Keywords:

Real time library, In loco library , Hybrid library, Information organization, Cyberculture, Virtual library, Digital library. 


\section{INTRODUÇÃO}

Com o intuito de contextualizar, histórica e culturalmente, as bibliotecas, quanto aos seus modelos de organização da informação, apresentaremos, por necessidade metodológica, as bibliotecas e as tecnologias por elas adotadas, as variações quanto às tipologias e a amplitude das definições adotadas. Em momento posterior serão apresentadas definições e tipologias para o reescalonamento das bibliotecas pelo ponto de vista do acesso, de modo a abandonar, desse modo, as qualificações que abordam a ambientação física, as tecnologias e o suporte à informação.

\section{BIBLIOTECAS E AS TECNOLOGIAS DA CONTEMPORANEIDADE}

Pela necessidade de a informação ser organizada de forma a poder ser utilizada posteriormente e pela existência de locais construídos especificamente para esse fim, traçaremos breves apontamentos de conceituações de bibliotecas para que sirvam de embasamento epistemológico para a proposição da conceituação adotada neste trabalho: Cícero (106-43 a.C.) emprega bibliothẽca,ae como "lugar em que se guardam livros" (HOUAISS; VILLAR, 2001, p. 443); etimologia francesa “bibliothéque” (1493), do grego biblion - "livro” + tẽkẽ - “caixa, depósito”, através do latim bibliothẽca,ae (op. cit., p. 444); “coleção de livros” (HOUAISS; VILLAR, loc. cit.); “edifício ou recinto onde ficam depositadas, ordenadas e catalogadas diversas coleções de livros, periódicos e outros documentos, que o público, sob certas condições, pode consultar no local, ou levar de empréstimo para devolução posterior” (HOUAISS; VILLAR, loc. cit.); biblioteca é uma coleção organizada de itens em vários formatos (livros, periódicos, vídeos, CDROMs etc.) com os serviços requeridos de modo a torná-los disponíveis a grupo ou grupos de usuários (TENNANT, 1999);

todo tipo de organização atuante na área de informação e/ou documentação, que trabalhe com os registros do conhecimento em todo e qualquer tipo de suporte, independentemente de sua designação. São consideradas unidades de informação todos os tipos de bibliotecas, mapotecas, centro / serviço / departamento / sistema de informação e/ou documentação, de acordo com sua área de atuação e extensão. (AMARAL, 1998, p. 15).

Como proposta deste trabalho, faz-se necessária compreender biblioteca como coleção de materiais para uso, após serem ordenados e catalogados, em qualquer suporte (as tecnologias de época assim se colocam: desde as tábulas de argila aos registros de 
computador), com uma política sistemática de formação do acervo (resultando em intenções, conscientes ou inconscientes, particulares ou institucionais) e preocupações voltadas tanto à preservação e ordem quanto ao acesso às suas coleções, para que se possa tirar proveito e oportunidade na condição de usuário, podendo também ter a função de ferramenta social ou de depósito para a memória da humanidade.

\subsection{As variegadas tipologias}

As sociedades, em geral, são tão dependentes da tecnologia quanto as bibliotecas. Segundo Cunha (2000), o acesso às bases de dados em substituição aos textos impressos, sucedâneos aos manuscritos, demonstra que as bibliotecas acompanharam os novos paradigmas tecnológicos. Borges, Oliveira e Pohlman Filho (1999, p. 3) ressaltam que a “transição da mídia impressa para a mídia digital afirma-se como passo decisivo para a criação de uma nova estrutura de bibliotecas onde a informação poderá ser acessada remotamente e compartilhada de forma quase instantânea”.

Amaral (2004), baseada em trabalho de Carrion Gútiez, traça um quadro sinóptico quanto às classificações de bibliotecas e a tipologia das informações acessadas, sumariando-as em: [1] biblioteca automatizada - acesso local às informações impressas com metainformações digitais; [2] biblioteca digital - acesso remoto às informações e metainformações digitais; [3] biblioteca híbrida - acesso local e remoto às informações impressas e digitais e às metainformações digitais; e [4] biblioteca tradicional - acesso local às informações e metainformações impressas.

Já Sharon e Frank, na Conferência Geral da IFLA (2000 apud CABRERA FACUNDO; COUTÍN DOMÍNGUEZ, 2005, p. 15), propuseram: [1] bibliotecas analógicas biblioteca em papel com catálogo manual; [2] bibliotecas automatizadas ou híbridas biblioteca analógica com catálogo informatizado; [3] biblioteca digital - biblioteca automatizada, com maior parte das informações em meio digital.

Ohira e Prado (2002), baseadas nos trabalhos de Marchiori (1997) e Pereira e Rutina (1999), propõem a divisão da história e evolução das bibliotecas em três momentos distintos: [1] biblioteca tradicional - etapa que compreende de Aristóteles até o início da automação em bibliotecas, caracterizada por espaço físico delimitado e serviços e produtos mecanizados; [2] biblioteca automatizada - fase em que há adoção de 
tecnologia computacional nos serviços meios e fins e acesso online aos bancos de dados por meio de redes; [3] biblioteca eletrônica - período em que há substituição do espaço físico pelo ciberespaço e acesso online a textos completos e informações digitalizadas.

Cunha (loc. cit.), entretanto, analisa a evolução das bibliotecas agrupando-as em: Era I tradicional moderna; Era II - automatizada; Era III - eletrônica; e Era IV - digital e virtual.

Percebe-se, portanto, com Drabenstott e Burman (1997, p. 183), que as opiniões quanto às fases evolutivas das bibliotecas são diversas. Às vezes são divididas em [1] “bibliotecas do tempo de Aristóteles até começos da fase de automação”, depois como [2] “modernas bibliotecas com seus serviços plenamente automatizados” e, finalmente, [3] a “fase contemporânea da biblioteca eletrônica”; e, em outros casos, em [1] "biblioteca em papel, seguida pela [2] bibliotecas de processos automatizados, e a [3] biblioteca digital, com artefatos armazenados eletronicamente”.

\section{Organização da informação na cibercultura}

Por considerarmos de relevância epistemológica e, também, por necessidade metodológica, propomos o reescalonamento das bibliotecas de acordo com o acesso e não quanto a ambientação física, as tecnologias adotadas ou ao seu suporte como as tipologias acima pressupõem.

Desse modo, propomos a divisão das bibliotecas em in loco, em tempo real e híbridas por prezarmos de fundamental relevância o vetor acesso como determinante na contemporaneidade, haja vista a formação de redes ${ }^{1}$ para transferência de informações, a reconfiguração do tempo e do espaço ora vigentes e a forma com que as tecnologias computacionais afetam a criação, o uso, a gestão e o fluxo da informação.

\subsection{Bibliotecas in loco}

As principais características da biblioteca in loco, que também pode assumir outras identificações como presencial, tradicional, física, palpável, off-line, corporalizada,

\footnotetext{
${ }^{1}$ Concordamos com a afirmação de McGarry (1999, p. 122), para quem o "conceito de rede abrange totalmente as atividades de comunicação humana" e afirma que "qualquer novo recurso, de qualquer tipo, tende a transformar as relações entre as pessoas” (ibid., p. 123).
} 
convencional e concreta, são: [1] ocupação pelo corpo, no momento do acesso, a uma instalação física definida, sendo possível visitá-la e ter “contato real com paredes, móveis, etc. e conteúdo” (ZANG et al., 2000, p. 220), de modo que [2] acervo e [3] catálogo utilizam o papel como suporte de registro da informação (CUNHA, 1999b, 2000; MORIGI, PAVAN, 2004). Acrescentaríamos, ainda, que esse tipo de biblioteca pode disponibilizar aos seus usuários produtos eletrônicos, como rádio, televisão, videocassete, DVD, computadores - porém sem acesso à rede -, no anseio de minimizar e recontextualizar a exclusão infotecnológica. É primordial enfatizar que, contemporaneamente, o acesso a esse tipo de biblioteca é feito pelos dromoinaptos. ${ }^{2}$

Quanto a ambientação física, “a biblioteca pode estar localizada em um único local ou distribuída”, de forma que esta pode ser em bibliotecas setoriais ou em locais longínquos (ZANG et al., op. cit., p. 222).

Na visão de alguns bibliotecários, e também para uma parte dos usuários por eles atendidos, a biblioteca sempre foi considerada um símbolo de estabilidade e constância. Muitas pessoas imaginam que ela deve ser um local para quietas reflexões e contemplações; um lugar em que, muitas vezes, as pressões do mundo agitado são minoradas ou quase expurgadas. (CUNHA, 1999b, p. 257).

Com esse formato a biblioteca existe desde o final da Idade Média.

Segundo Morigi e Pavan (op. cit.), verifica-se que, em períodos em que os registros eram em papel, havia um maior contato entre o bibliotecário, sempre presente, e os usuários, sendo marcada a interação face-a-face e a comunicação oral. Os autores, em outro momento (MORIGI; PAVAN, 2004), afirmam que o contato era mantido por relações visíveis ao olho humano, de forma que, como organização, era capaz de criar sociabilidade ou, ao menos, referendar tipos de sociabilidade definidos historicamente.

Para Cunha (1999b), porém, no final do século XIX, houve uma grande revolução na configuração das bibliotecas com a adoção do catálogo em fichas e não mais sob a forma de livros. Para Zang et al. (2000, p. 222), outra grande mudança a ser considerada é o momento em que a função primordial “deixa de ser principalmente a guarda e manutenção do acervo e passa a ser a localização e a recuperação de informações não mais restritas ao seu ambiente físico”. Entendemos, contudo, que mesmo em casos de

\footnotetext{
${ }^{2}$ Cf. Zafalon, 2005.
} 
obtenção de recursos informacionais em outras bibliotecas, há a necessidade do deslocamento físico até a unidade concreta de conhecimento registrado e a provisão de cópias em papel, representando, da mesma forma, o saber materializado e o poder constituído pelas gerações.

Cunha (2000) afirma que, todavia, no decorrer dos tempos, tornou-se dificultoso prover acesso à demanda informacional dos usuários. O maior investimento recaía sobre o registro de informações catalográficas, indicando ao usuário o documento. Ou seja, o foco era a automação dos catálogos bibliográficos, índices e mecanismos de descrição bibliográfica. Em outro trabalho (id., 1999b), o autor afirma que a explosão bibliográfica, o crescente custo para aquisição e a constante necessidade de alocação física dos documentos podem ser as causas da impossibilidade em adquirir o que se publica.

Foskett (1984 apud GUSMÃO, 2001, p. 13) relata: “Os serviços da biblioteca transcendem o tempo e o espaço, e pela organização de seus documentos para uso ativo torna disponível a sabedoria dos séculos e a experiência diária”. Isso pode ser reafirmado com Cunha (1999b, p. 261) que considera, a título de exemplo, o fato de que as bibliotecas universitárias, "tradicionalmente utilizaram políticas de desenvolvimento de coleções que antecipavam as possíveis necessidades de informação de sua clientela”. Porém, há que se considerar a ressalva feita por Demas (1994 apud CUNHA, loc. cit.), de que "o tamanho do acervo terá diminuição da sua importância, pois o que irá contar, daqui para frente, não são os milhões de itens do acervo, mas as opções para acessar a informação demandada”.

Drabenstott e Burman (1997, p. 181) acenam como problemas identificados, por diversos autores, em relação à coleção de materiais impressos, em constante coleta,

altos preços de materiais impressos e [o] respectivo armazenamento em estantes e similares; [o] contínuo número de itens disponíveis para compra, com o agravo de repetição de conteúdos; as duplicações de operações catalográficas e de coleções em bibliotecas do mesmo tipo e áreas do conhecimento; [a] necessidade contínua de espaço e aquisição de estantes para armazenar materiais e para acomodar usuários, cujo cálculo para redução de espaço de armazenamento para a informação digital é cada vez maior; [a] redução de orçamentos e/ou de suas porcentagens; [a] crise com os seriados, devido à elevação e custos com assinaturas de revistas especializadas; [e as] despesas mais altas com materiais de encadernação, declinando compras. 
Objetivando reforçar a importância da biblioteca como organização baseada na geração, disseminação e fluxo de informações e como instituição voltada para o desenvolvimento social, as bibliotecas redefinem, constantemente, seus produtos e serviços. Assim, passaram a utilizar técnicas e processos diferenciados de acordo com o suporte da informação, bem como em relação ao seu armazenamento, registro e recuperação. Isso, de acordo com Cabrera Facundo e Coutín Domínguez (2005), faz com que haja necessidade de constantes e amplas formas de avaliação, de modo a considerar imbricados vários pontos, como: serviços, coleção, objetivo, pessoal, instalações, atividades entre as várias bibliotecas, recursos financeiros etc.

Para o porvir, Drabenstott e Burman (1997, p. 181) afirmam:

no caso da biblioteca tradicional, daqui a 20 ou 50 anos, coleções estarão deterioradas; novas edificações serão necessárias para acomodação de milhares de documentos recém-publicados; novas funções serão atribuídas aos bibliotecários; coleções de valor histórico deverão ser encaminhadas a museus e o resto será reciclado.

\subsection{Bibliotecas em tempo real}

O processo de adoção de tecnologias se faz presente nas sociedades, desde a Idade da Pedra, e, desse modo, as bibliotecas não teriam como fugir a isso. Entretanto, faz-se necessária a compreensão do contexto histórico, econômico e cultural no qual essas mudanças emergem. Há duas décadas, diversas transformações têm início, alcançando uma velocidade e profundidade vertiginosas, com a proliferação do uso das tecnologias de informação.

Como instituição social, a biblioteca possui longa e complexa experiência com as tecnologias vigentes a cada época: “imprensa, máquina de escrever, telefone, telex, mimeógrafo, microfilme, cartão perfurado nas margens, computador, disco ótico e redes eletrônicas” (CUNHA, 1999b, p. 257). Levacov (1997, p. 133) deixa claro que a automatização "permitiu que as bibliotecas melhorassem novamente, expandissem e agrupassem atividades e serviços mais úteis para usuários e staff”'.

Desse modo, entende-se, como premente, a expressão das idéias, compiladas por Cunha (1997), de autores que, no período de 1945-1985, previram a necessidade de mudanças 
nas bibliotecas tradicionais e que imaginaram a utilização de recursos tecnológicos de modo a melhorar o acesso à informação: [1] Vannevar Bush (1945) - imaginou uma máquina (denominada Memex) que facilitaria a disseminação da informação cientifica na qual seria possível armazenar, para uso posterior, toda a informação de interesse; é considerado o pai da biblioteca digital; [2] Albert G. Hill (1951) - propôs a idéia de uma biblioteca eletrônica que facilitasse o acesso à informação por parte do pesquisador que, mediante perfis de interesses armazenados no computador, poderia receber e enviar informações relevantes para as suas atividades; [3] Theodor Holm Nelson (1965) apresentou uma biblioteca eletrônica Xanadu na qual poderiam ser armazenados textos integrais de documentos; é o idealizador do hipertexto; [4] J. C. R. Licklider (1965) seguidor das idéias de Bush, sugeriu a criação de uma biblioteca eletrônica por considerar o livro como suporte inadequado de informação; [5] John Kemeny (1965) - afirmou que a biblioteca do futuro dependeria fortemente da automação e que o acesso à informação seria feito por meio de redes automatizadas; [6] Edwin B. Parker (1970) - previu que, até 1975, os catálogos em linha estariam disponíveis e que, em 1985, o acervo bibliográfico mundial estaria armazenado em computadores; imaginou uma máquina que teria tela e teclado, contendo as funções de uma biblioteca e de um jornal, com a capacidade de acessar redes de informação por meio da linha telefônica; [7] Robert S. Taylor (1972) propôs a necessidade de abandono do conceito tradicional de biblioteca como depositária da informação e a adoção de um novo conceito de comunicação científica que transcendesse as estruturas físicas da biblioteca; [8] F. W. Lancaster (1978 e 1982) comentou suas idéias sobre a sociedade sem paredes na qual a biblioteca tradicional seria substituída pela biblioteca digital; [9] Kenneth Dowlin (1984) - apresentou a idéia de criação de uma biblioteca eletrônica na qual o rápido acesso à informação por meio de sistemas de comunicação eletrônica deveria ser enfatizado.

Todas essas inovações, vistas como necessárias a ponto de serem incorporadas ou abandonadas pelas bibliotecas tradicionais, encontram-se, contemporaneamente, sob diversas designações: digital, eletrônica, virtual, biônica, sem paredes, livros sem páginas, do futuro, máquina eletrônica, online, imaterial, binária, global, multimídia, lógica, metabiblioteca, transbiblioteca (DRABENSTOTT, BURMAN, 1997; ORTIGARI, 1999, SALARELLI, 2000; SANTORO, 2003 apud ALENCAR, 2004, p. 2). Essas definições podem dar uma noção da intensidade das mudanças em curso. A mais profunda mudança, o acesso remoto às fontes de informação, ocorreu a partir da grande 
difusão do uso da Internet, de modo que Levacov (1997, p. 126) afirma: “a biblioteca deixa de ser um tranqüilo depósito de livros para tornar-se o ponto focal de pesquisa variada, acessada a qualquer hora por usuários virtuais de vários lugares do mundo”.

Julgamos indispensável a apresentação das diversas conceituações com o objetivo de levantar o constructo necessário para a explanação da definição a ser adotada. Enfatizamos que tais conceituações foram preteridas por não haver consenso entre os próprios autores, por elas não apresentarem especificidade, clareza e distinção e por não satisfazerem o foco principal desta pesquisa: o acesso à informação.

As conceituações levantadas e compiladas sobre a biblioteca eletrônica são: [1] biblioteca que consiste de materiais e serviços eletrônicos; materiais eletrônicos podem incluir todos os materiais digitais, bem como uma variedade de materiais de formatos analógicos que requerem eletricidade para uso; como exemplo temos os videotapes que são formatos analógicos e requerem uso de equipamento eletrônico (TENNANT, 1999); [2] biblioteca “formada por material primário essencialmente em formato eletrônico”; "não se refere à automação da biblioteca”; “não se trata apenas da Internet, pois todos concordam que a Internet é anárquica”; “não se trata de conjunto de dados secundários” (ROWLEY, 2002, p. 20); [3] "uma coleção organizada e administrada de informações numa variedade de meios (texto, imagem fixa, imagem em movimento, som, ou suas combinações), porém todos em formato digital” (OPPENHEIM, 1997 apud ROWLEY, op. cit., p. 4); [4] "biblioteca fisicamente identificável, [...] que não possui material impresso [...] e faz parte de uma biblioteca virtual” (COLLIER et al., 1993 apud ROWLEY, loc. cit.); [5] biblioteca que pode ter presença física (“enquanto a biblioteca virtual, posto que é percebida como transparente, [pode possuir] instalações físicas transparentes e bibliotecários transparentes”) (BECKMAN; PEARSON, 1993 apud ROWLEY, loc. cit.); [6] “ambiente administrado de materiais multimídia em formato digital, destinado a beneficiar a população de usuários, estruturado para facilitar o acesso a seu conteúdo e equipado com recursos de auxílio à navegação na rede global”; “ligada a um espaço físico ao qual as pessoas recorrem em busca de serviços fornecidos de forma eletrônica” (ROWLEY, op. cit., p. 20); [7] biblioteca na qual “os processos básicos [...] são de natureza eletrônica, o que implica ampla utilização de computadores e de suas facilidades na construção de índices on-line, na busca de textos completos e na recuperação e armazenagem de registros” (BARKER, 1994 apud MARCHIORI, 1997, p. 118). 
Já biblioteca digital pode congregar as seguintes definições: [1] biblioteca com informações existentes somente na forma digital, armazenada em diferentes meios, “como as memórias eletrônicas (discos magnéticos e óticos)”; “não contém livros na forma convencional e a informação pode ser acessada, em locais específicos e remotamente, por meio de redes de computadores” (BARKER, 1994 apud MARCHIORI, 1997, p. 118); [2] biblioteca com conteúdo composto de "hiperlivros e livros-virtuais"; pode ser vista "como uma livraria com uma imensa disponibilidade de livros, levada a efeito pela conexão em rede de um número crescente de bibliotecas” (LANDONI et al., 1993 apud MARCHIORI, op. cit., p. 119); [3]

conjunto de 'recursos de informação em formato digital', inseridos em um 'contexto organizacional' que procura selecionar, registrar e sistematizar para tornar disponível e que permite, 'mediante recursos de telecomunicações, o acesso local ou a distância' por parte de uma comunidade de 'usuários locais ou remotos' (AMARAL, 2004);

[4] biblioteca que consiste de materiais e serviços digitais; materiais digitais são itens que podem ser armazenados, processados e transferidos em mecanismos digitais (binário) e redes; serviços digitais são serviços (como um serviço de referência) oferecidos novamente em redes digitais (TENNANT, 1999); [5]

organizações que fornecem os recursos, incluindo o pessoal especializado, para selecionar, estruturar, oferecer acesso intelectual, traduzir, distribuir, preservar a integridade e garantir a permanência das coleções digitais, de tal forma que elas estejam disponíveis para uma ou várias comunidades. (YORK, 2002 apud AQUINO, 2004, p. 12);

[6] “coleção organizada de dados multimídia com métodos de gerenciamento da informação, que representa os dados como informação útil e conhecimento para o povo numa variedade de contextos sociais e organizacionais" (GRIFFIN, [s. d.] apud CUNHA, 1999a, grifo do autor); [7]

te [b1]que dispõe de uma coleção pública ou privada de livros, documentos ,nicos ou congêneres, organizada para estudo, leitura e consulta. Organizadas por estantes virtuais [em ordem de autor, gênero ou obra] e que guardam e/ou ordenam arquivos de documentos eletrônicos, onde os leitores de todo o mundo acessam e fazem download a partir de um único servidor ou de vários servidores interligados (PROCÓPIO, 2005, p. 89, colchetes do autor); 
conjunto de computação, armazenamento, e maquinaria de comunicações digitais juntamente com conteúdo e software necessários para reproduzir, emular, e estender os serviços fornecidos pelas bibliotecas convencionais com base em papéis e outros meios materiais para reunir, catalogar, buscar, e disseminar informações. Um serviço completo de biblioteca digital deve realizar todos os serviços essenciais das bibliotecas tradicionais, e também explorar as conhecidas vantagens do armazenamento, busca, e comunicação digitais (GLADNEY, 1994 apud ALENCAR, 2004, p. 3);

[9] “ambiente que reúne coleções, serviços, e pessoas para apoiar o ciclo completo de criação, disseminação, discussão, colaboração, utilização, nova autoria, preservação de dados, informações, e conhecimento”; não é equivalente “a uma coleção digitalizada com ferramentas de administração de informações” (ATKINS, 1997 apud ALENCAR, loc. cit.); [10] "conjunto de meios eletrônicos e habilidades técnicas associadas para criação, busca, e uso de informações”; “extensão e otimização do armazenamento das informações, e dos sistemas de recuperação que manipulam dados digitais em qualquer meio (texto, imagens, sons; imagens estáticas ou dinâmicas) e existem nas redes distribuídas"; seu conteúdo “inclui dados e metadados que descrevem vários aspectos dos dados (por exemplo, representação, criador, proprietário, direitos de reprodução)”; “construídas, reunidas, organizadas por (e para) uma comunidade de usuários [...] [com] habilidades funcionais [que apóiam] as suas necessidades de informações e usos”; “constituição de comunidades nas quais indivíduos e grupos interagem entre si, utilizando dados, informações, e fontes de conhecimento e sistemas”; “extensão, otimização, e integração das várias instituições de informações como lugares físicos onde recursos são selecionados, reunidos, organizados, preservados, e acessados no apoio a uma comunidade de usuários” (BORGMAN, 1998 apud ALENCAR, 2004, p. 4); [11]

ambiente digital presente na web ou em redes locais suportada por profissionais que realizam a busca, recuperação, tratamento, indexação e digitalização de acervos em diversos formatos (vídeo, áudio, imagem e texto), combinando serviços da biblioteca tradicional tais como indexação e organização da informação, associando esses serviços aos recursos e serviços digitais, servindo a uma comunidade, seja ela mundial ou específica, e possibilitando interações entre os seus usuários (ALENCAR, op. cit., p. 6).

Cunha (1999b, p. 258) aponta, como características encontráveis nas bibliotecas digitais: acesso remoto pelo usuário, por meio de um computador conectado a uma rede; utilização simultânea do mesmo documento por duas ou mais pessoas; inclusão de produtos e serviços de uma biblioteca ou centro de informação; existência de coleções de documentos correntes onde se pode acessar não-somente a referência bibliográfica, mas também o seu texto completo [...]; provisão de acesso em linha a outras fontes externas de informação [...]; utilização de maneira que a biblioteca 
local não necessite ser proprietária do documento solicitado pelo usuário; utilização de diversos suportes de registros da informação tais como texto, som, imagem e números; e existência de unidade de gerenciamento do conhecimento.

Finalmente, biblioteca virtual poderia ser conceituada como: [1] bibliotecas que existem somente virtualmente - isto é, não existe na "vida real”; pode ser composta de materiais de uma variedade de bibliotecas separadas e que foram organizadas no espaço virtual, usando computadores e redes de computadores (TENNANT, 1999); [2] biblioteca que “não implica localização física, seja para o usuário final, seja para a fonte”; a informação pode ser acessada “de qualquer ponto [e pode] estar em qualquer lugar”; “é irrelevante para o usuário saber onde a informação é mantida”; “é acessada e fornecida pelas redes de comunicações”; “pode ser oferecida pela biblioteca eletrônica, mas a recíproca não é verdadeira” (ROWLEY, 2002, p. 21); [3] biblioteca relacionada ao "conceito de acesso, por meio de redes, a recursos de informações disponíveis em sistemas de base computadorizada, normalmente remotos” (POULTER, 1994 apud MARCHIORI, 1997, p. 118); [4] biblioteca que

implica integração eletrônica de novos serviços com os serviços tradicionais de bibliotecas, podendo ser tão limitada como um OPAC3, ou tão compreensiva como a utilização de redes de computadores e recursos eletrônicos para a notificação de reuniões, novos desenvolvimentos em conjunto com outras bibliotecas e a disponibilidade em rede de livros, relatórios e artigos (CLOYES, 1994 apud MARCHIORI, op. cit., p. 119);

[5] biblioteca que pressupõe

acesso remoto aos conteúdos e serviços de bibliotecas e outros recursos de informação, combinando uma coleção interna de materiais correntes e fartamente usados em ambas as formas (eletrônica e impressa), com redes eletrônicas que provêm acesso e a transferência de fontes de conhecimento e de informação, com bibliotecas e instituições comerciais externas em todo o mundo [(GAPEN, [s. d.] apud PIGGOTT, 1993; SAUNDERS, 1995) apud MARCHIORI, loc. cit., p. 119];

[6] "biblioteca que, para existir, depende da tecnologia da realidade virtual” e que se utiliza de recursos de software simulador de ambiente de biblioteca (com imagens tridimensionais na tela do computador), que possibilitam entrar e circular pelas suas prateleiras (BARKER, 1994 apud MARCHIORI, op. cit., p. 118); [7] biblioteca que dissemina informação seletiva diretamente ao usuário da biblioteca, em geral por via

\footnotetext{
${ }^{3}$ A abreviação de OPAC é utilizada para referir-se a OnLine Public Access Catalog. 
eletrônica, com pouco ou nenhum acervo de livros e periódicos, salas de leitura, ou pessoal técnico (POWELL, 1994 apud MARCHIORI, 1997, p. 119); [8]

biblioteca mais tradicional que transformou alguns pontos significativos de seus canais de busca de informação em formato eletrônico, para que muitos ou o máximo de seus clientes não precisem visitar fisicamente a biblioteca para obter informação (POWELL, 1994 apud MARCHIORI, loc. cit.);

[9]

biblioteca que opera como uma conexão de atividades de gerenciamento de informações selecionadas dentro da organização, algumas delas centralizadas, mas a maioria das quais acontecendo por meio de esforços de um staff descentralizado, de recursos e sistemas e mesmo de fornecedores externos, que estão acessíveis e dispersos por toda a organização (POWELL, 1994 apud MARCHIORI, loc. cit.);

[10] biblioteca que se utiliza de "computação avançada em alta velocidade e [de] possibilidades de telecomunicação de acesso e distribuição dos recursos informacionais” (ROOKS, 1993 apud PEREIRA, 1995, p. 5).

Em texto de Drabenstott e Burman (1997, p. 181), Neusa Dias de Macedo apresenta, como condensadora do documento das autoras, definição e interpretação própria para a biblioteca do futuro:

a biblioteca digital, biônica, transmitida eletronicamente em rede - a biblioteca do
século XXI - vem a ser uma potente, transparente e universal provedora de
informação, também chamada de biblioteca sem paredes. Não deixa de ser uma
máquina: a máquina virtual, que, utilizando a informática e as
telecomunicações, possibilita acesso a um reservatório diversificado e infinito de
dados e conhecimento. Cerca vários tipos de recursos informacionais, como
bibliotecas formais/convencionais, bases de dados, textos ou fontes eletrônicas,
arquivos e os mais dinâmicos artefatos digitais, que, de modo formal ou informal,
ultrapassam os materiais tradicionais impressos, vindos das mais diversas partes
do mundo. Um grande número de usuários, tanto em nível pessoal, comercial ou
acadêmico, pode acessá-la em terminais simultaneamente por conexão a redes
eletrônicas internacionais, utilizando endereços eletrônicos e senhas. Novos
recursos pelo rádio-vídeo e outros mecanismos tecnológicos e telemáticos a
serem criados prometem superar ainda mais o acesso à informação, futuramente.
(Grifo do autor). Para fins deste trabalho, consideraremos biblioteca em tempo real aquela com coleção de informações ou de unidades documentárias de quaisquer natureza (texto completo, imagem fixa ou em movimento, som, em suas variadas combinações, e assim por diante), organizadas no espaço virtual, com base em objetivos determinados em prol de usuários com necessidades específicas, inseridos ou não em um contexto organizacional, que não têm como freqüentar, presencialmente, o ambiente, por estar alhures. Pode consistir de materiais de diferentes bibliotecas, com armazenamento em diferentes meios e com uso 
de memórias eletrônicas, que podem ser criadas, armazenadas, organizadas, processadas e distribuídas com apoio de redes de telecomunicações e com possibilidade de abranger grande variedade de aplicativos. Tem acervo definido pelo acesso e não pela posse em si, de modo a disponibilizar, imaterialmente, a unidade documentária, independente de instância física e de significação de tempo ordinário, prescindindo, portanto, de rede, usuário e acesso em tempo real.

\subsection{Bibliotecas híbridas}

Como destacado anteriormente, o ritmo acelerado de produção e disseminação de informações, com o advento das tecnologias em rede, exigiu que as unidades de informação fossem em busca de infra-estrutura compatível com a demanda. No Brasil, de acordo com Martinelli (1998 apud CÔRTE, 2000, p. 6), o processo de informatização das bibliotecas teve início com as mudanças na política de informática, a partir de 1993. A transmissão eletrônica de informações direciona a biblioteca a melhor disponibilizar as unidades documentárias, embora problemas ainda possam existir.

É premente ressaltar que muitas bibliotecas estão em fase de transição, o que, de acordo com Drabenstott e Burman (1997, p. 184), demonstra que, com as novas tecnologias, a biblioteca convencional não será abolida, mas que em seu acervo coexistirão, tanto livros quanto programas computadorizados, tendo, como princípio orientador, o uso da tecnologia apropriada a cada propósito particular. Apesar de essa colocação ter sido feita há 10 anos, vimos como relevante e realista.

Embora a infovia tenha a capacidade de possibilitar, a partir do ponto de vista de alguns autores, maior acessibilidade às informações internacionais, não parece que milhões de materiais que utilizaram o papel para o registro da história humana nos últimos séculos sejam convertidos em formato digital de forma abrangente.

Julgamos indispensável a apresentação das diversas conceituações adotadas para conceituar o que pretendemos expor como bibliotecas híbridas. Barker (1994 apud MARCHIORI, 1997, p. 118) utiliza o termo polimídia para denotar os vários meios em que a informação pode ser armazenada. Adotando-se essa linha de raciocínio, segundo o autor, as bibliotecas que armazenam, processam e disseminam informações em diversos suportes podem ser identificadas como polimídias. Amaral (2004) restringe-se a afirmar 
que a biblioteca híbrida trata de informações impressas e digitais, com serviços locais e remotos, constituindo-se de novas e velhas funções, e Zang et al. (2000, p. 222) afirma que o acervo tanto pode ser impresso como pode ser digitalizado, de modo que o acesso convencional passa a ser substituído pelo remoto. Martins (2003, p. 9), ao conceituar biblioteca universal, une acervos reais e virtuais e define que os objetos deixariam de estar conectados ao suporte impresso para assumir o "processo impresso, visual, audiovisual, oral, tatual, multimídia e virtual”. Para o autor, o conceito de informação, na biblioteca assim concebida, volta-se para a disponibilização, quer seja na biblioteca presencial, com documentos reais, quer seja consultando documentos virtuais, na rede, alterando-se a cultura de materiais fixos nas estantes.

Para Dertouzos (1998, p. 241),

as bibliotecas continuarão com a custódia dos materiais educativos sólidos, com destaque para os livros. Mas elas se tornarão também gerenciadores de linhas de comunicação com outros locais de conhecimento, com a condição de que as bibliotecas físicas controlem a qualidade das bibliotecas virtuais, decidindo quais conhecimentos existentes em outras instituições merecem menção pelos selecionadores e hiperorganizadores da biblioteca local. [...] O gerenciamento eficaz desses selecionadores de conhecimento será crucial para a qualidade das instituições de ensino no futuro [...].

Garcez e Rados (2002, p. 45 et seq.) intitulam biblioteca híbrida como o conceito mais adequado para satisfazer as atuais necessidades informacionais, o estado transacional das bibliotecas: aquela designada a agregar diversas tecnologias e fontes, cujo acervo não é completamente impresso e tampouco digital, "utilizando tecnologias disponíveis para unir, em uma só biblioteca, o melhor dos dois mundos” (GARCEZ; RADOS, op. cit., p. 47). Os autores, ao citarem Rusch-Feja, afirmam que a biblioteca híbrida “deve integrar o acesso a diferentes tecnologias para o mundo da biblioteca digital e através de diferentes mídias” (1999 apud GARCEZ; RADOS, op. cit., p. 45). Ao mencionarem Sabattini, afirmam que "o sistema futuro terá de unificar materiais de muitas bibliotecas existentes em diferentes formatos, linguagem, e sumarizar a informação encontrada de tal modo que se torne fácil e rápido para o usuário navegar pelo mesmo” (1999 apud GARCEZ; RADOS, 2002, p. 46). Ao referirem-se a Rusbridge, afirmam que seria "importante integrar estas mídias e acabar com a incompatibilidade existente entre as várias fontes de informações [...]” (1998 apud GARCEZ; RADOS, op. cit., p. 45). 
Entretanto, como o foco deste trabalho para a designação das bibliotecas está no acesso e não no suporte, consideraremos como bibliotecas híbridas aquelas que não só possuem acervo constituído em formato analógico e digital, que adotam grande diversidade de mídias, mas aquelas em que o acesso, feito fisicamente em um locus definido (como o da biblioteca in loco apresentado anteriormente), em modo presencial, possibilita tanto o acesso às bibliotecas em tempo real como aos itens materiais, isto é, tanto atômico quanto binário. Essencialmente são constituídas de um espaço físico dedicado à biblioteca, com acervo de livros, periódicos, vídeos, microfilmes, software de computadores etc., com processos muitas vezes automatizados, no qual o usuário vai até a biblioteca em tempo real sem de fato ir ou, não se sabe ao certo, se é a informação que vem até ele. ${ }^{4}$

Nessas bibliotecas, as bases de dados remotas constituem ferramentas indispensáveis no processo de acesso às informações, tanto referenciais - com resumo ou não - como em texto completo.

Amaral e Guimarães (2000, p. 2) relatam que um número cada vez maior de bibliotecas

se utilizam da Internet para alcançar seus objetivos de forma mais efetiva, utilizando o ciberespaço para oferecer serviços e produtos, fornecer informações institucionais, estabelecer comunicação com seus públicos, servir como portal para outras fontes de informação de interesse de seus públicos, fazer promoção, alcançar um maior número de usuários, em menor tempo e com a possibilidade de custos razoáveis dentre outros.

Entretanto, não vimos essa situação como abrangente na definição, por nós sugerida e adotada, por desconsiderarmos a Internet como base de dados organizada e voltada para público específico e, ainda, por focarmos o ciberespaço somente como uma nova forma de comunicação.

Para Penniman (1993 apud LANCASTER, 1994, p. 10) as bibliotecas devem enfatizar e avaliar a política de distribuição das informações, firmando alianças de pesquisa. Garcez e Rados (op. cit., p. 46) reafirmam a postura de necessidade de compartilhamento de recursos como o único meio de satisfazer as demandas de forma a assegurar acesso aos recursos disponíveis nas várias bibliotecas institucionais. Entendemos que, nas diversas situações que podem ser vivenciadas nessa biblioteca, cabe aos administradores da

\footnotetext{
${ }^{4}$ Quanto a este trecho - acerca do ir sem que haja deslocamento físico - baseamo-nos em Virilio (1993, p.
} 
unidade informacional [1] integrar a gama de serviços disponíveis, [2] estabelecer uma estrutura adequada à nova filosofia de oferta de produtos e serviços e [3] redesenhar práticas e processos no intuito de demonstrar aos usuários na diversidade de oportunidades voltadas para as suas demandas, apesar de se defrontarem com problemas oriundos das condições de acesso, de dificuldade de tomada de decisão acerca do desenvolvimento e formação do acervo.

Cabe ressaltar que, nessa nova realidade de processo massificado de adoção de novas tecnologias como ferramentas constituintes da nova prática profissional dos bibliotecários e agentes de informação, houve alteração, segundo Morigi e Pavan (2004, p. 124-125), nas formas de subjetivação da profissão e nas formas de sociabilidade, o que implica redimensionamento dos papéis sociais, reinterpretação das práticas de gerenciamento da informação e dos serviços e mudança "na construção, na apreensão e na articulação do conhecimento da sociedade contemporânea”.

Desse modo, para melhor identificar a necessidade de interação interpessoal dos bibliotecários, Garcez e Rados (2002) classificam os usuários de bibliotecas híbridas em [1] usuário presencial: usuários ligados a instituições de ensino, geograficamente próximos à sede física da biblioteca, que, no processo de busca por informações, podem receber ou não a intermediação de gerenciadores do processo; [2] usuário off campus: usuários ligados a instituições de ensino, embora distantes geograficamente das bibliotecas, que podem ou não ser intermediados pelos gerenciadores da informação; [3] usuário remoto: usuários que não necessariamente têm vínculo com a instituição provedora e o processo de acesso às informações pode ocorrer via correio eletrônico, telefone ou fax; e [4] bibliotecas participantes e cooperantes: bibliotecas que tanto podem utilizar-se dos serviços de outra biblioteca como podem prestar atendimento, simultaneamente, "tanto a seus usuários locais, off campus e remotos, [quanto] às bibliotecas que participam de sistemas de rede” (ibid., p. 48).

Embora Barker (1994 apud MARCHIORI, 1997, p. 117-118) identifique as funções de “arquivo de conhecimento, preservação e manutenção da cultura, [de] disseminação de conhecimento, [de] compartilhamento de conhecimento, [de] recuperação de informação, [de] educação [e de] interação social”, propomos, porém, a reavaliação destas pelos

11) e Trivinho (2003, p. 117).

(C) Revista Digital de Biblioteconomia e Ciência da Informação,Campinas, v.6, n. 1, p. 61-83, jul/dez. 2008- ISSN: 1678-765X. 
sistemas de bibliotecas no que permeia não só a biblioteca híbrida, mas também aquela em tempo real.

\section{4 À guisa de conclusão}

No decorrer do trabalho e em pesquisa bibliográfica quanto às bibliotecas digitais, virtuais ou quaisquer outros termos que arrolem o desenvolvimento de bibliotecas na contemporaneidade, observa-se a necessidade de aprimoramento dos questionamentos crítico-conceituais adotados até o momento. Qualquer que seja a unidade documentária a ser disponibilizada, os atuais projetos de construção de bibliotecas em tempo real deverão, inevitavelmente, requerer um processo de revisão dos modelos ultimamente em uso, abarcando, inclusive, as funções dos profissionais envolvidos, a preservação, legibilidade e acessibilidade de documentos digitais por programas específicos.

Embora vantagens possam ser encontradas as vimos como acríticas, utópicas e ideológicas. Por considerarmos que mudanças ocorrem, não sem riscos, julgamos imprescindíveis a reflexão e a análise dos processos tecnologicizados. Entendemos como imaturos os posicionamentos em defesa das vantagens conferidas às bibliotecas em tempo real em relação às bibliotecas in loco. Não há, a nosso ver, vantagens, mas, novas necessidades diante do contemporâneo - aqui lembramo-nos de Baudrillard ao afirmar que a cada nova tecnologia há uma nova necessidade! Acerca da propalada liberdade, pelos usuários, no gerenciamento das pesquisas em bibliotecas em tempo real, nós a encaramos como inexistente, pois, o produtor e o gerenciador destas bibliotecas é quem decide, a priori, quais os arquivos, os links, os hipertextos, os textos integrais, as metainformações etc. a serem disponibilizados(as). Há que se discutir o fato de as bibliotecas sem paredes apresentarem novos muros, desta vez, ideológicos, burocráticos, legais e excludentes, por termos que considerar a impossibilidade de todos os cidadãos terem pleno domínio das senhas infotecnológicas de acesso.

\section{Referências}

ALENCAR, A. F. Bibliotecas digitais: uma nova aproximação. Informação \& Sociedade: Estudos, João Pessoa, v. 14, n. 1, p. 1-13, 2004. Disponível em: 
$<$ http://www.informacaoesociedade.ufpb.br/ojs2/index.php/ies/issue/view/10>. Acesso em: 28 jul. 2006.

AMARAL, S. A. A. Gestão dos serviços de informação digital. In: CICLO DE PALESTRAS: SISTEMAS DE INFORMAÇÃO NO LEGISLATIVO, 2004, Brasília. Anais eletrônicos... Brasília: Information Resource Center, 2004. Disponível em:

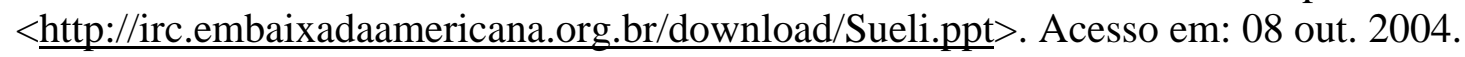

. Marketing: abordagem em unidades de informação. Brasília: Thesaurus, 1998.

AMARAL, S. A. A.; GUIMARÃES, T. P. Sites das bibliotecas universitárias brasileiras: estudo das funções desempenhadas. In: SEMINÁRIO NACIONAL DE BIBLIOTECAS UNIVERSITÁRIAS, 12., 2000, Recife. Anais... Recife: SNBU, 2000. p. 1-15. 1 CDROM.

AQUINO, M. A. Metamorfoses da cultura: do impresso ao digital, criando novos formatos e papéis em ambientes de informação. Ciência da Informação, Brasília, v. 33, n. 2, p. 7-14, maio/ago. 2004.

ATKINS, D. E. Report of the Santa Fe planning workshop on distributed knowledge work environments: digital libraries. 1997. Michigan: University of Michigan School of Information, 1997. Disponível em: <http://www.si.umich.edu/SantaFe/> . Acesso em: 20 fev. 2004.

BARKER, P. Electronic libraries: visions of the future. The Electronic Library, v. 12, n. 4, p. 221, Aug. 1994.

BORGES, K. S.; OLIVEIRA, J. B.; POHLMAN FILHO, O Ensino a distância, bibliotecas digitais e direitos autorais. In: WORKSHOP DE INFORMÁTICA NA ESCOLA, 5., 1999, Rio de Janeiro. Anais eletrônicos... Rio de Janeiro: Sociedade Brasileira de Computação, 1999. p. 1-12. Disponível em: $<$ http://www.bibdigital.pucrs.br/bibdigital/acervo/artbibdigwie99.pdf>. Acesso em: 13 maio 2004.

BECKMAN, M.; PEARSON, E. M. Understanding the needs of users: the timeliness factor. In: Helal, A.H.; Weiss, J. (ed.). Opportunity 2000: understanding and serving users in an electronic library: $15^{\text {th }}$ International Essen Symposium. Essen: Universitätsbibliothek, 1993. p. 307-321.

BORGMAN, C. L. What are digital libraries? Competing visions. Special Issue on Digital Libraries, Los Angeles, 23 out. 1998. Disponível em: <http://fox.cs.vt.edu/ fox/borgmanr.pdf > . Acesso em: 20 fev. 2004.

CABRERA FACUNDO, A. M.; COUTÍN DOMÍNGUEZ, A. Las bibliotecas digitales. Parte I: consideraciones teóricas. ACIMED, v. 13, n. 2, p. 1-27, 2005. Disponível em: $<$ http://bvs.sld.cu/revistas/aci/vol13_2_05/aci04204.htm>. Acesso em: 03 maio 2006.

CLOYES, K. The journey from vision to reality of a virtual library. Special Library, v. 85, n. 4, p. 253-257, Fall 1994. 
COLLIER, M. W. et al. The electronic library: virtually a reality? In: Helal, A.H.; Weiss, J. (ed.). Opportunity 2000: understanding and serving users in an electronic library: $15^{\text {th }}$ International Essen Symposium. Essen: Universitätsbibliothek, 1993. p. 136-146.

CÔRTE, A. R. A biblioteconomia frente às inovações tecnológicas. São Paulo: APB, 2000. (Ensaios APB, 85).

CUNHA, M. B. Biblioteca digital: aspectos econômicos. 1999a. Disponível em: $<$ http://www.ime.usp.Br/ cesar/simposio99/murilo/sld001.htm>. Acesso em: 14 out. 2006.

. Biblioteca digital: bibliografia internacional anotada. Ciência da Informação, Brasília, v. 26, n. 2, p. 195-213, maio/ago. 1997.

. Construindo o futuro: a biblioteca universitária brasileira em 2010. Ciência da Informação, Brasília, v. 29, n. 1, p. 71-89, jan./abr. 2000.

. Desafios na construção de uma biblioteca digital. Ciência da Informação, Brasília, v. 28, n. 3, p. 257-268, set./dez. 1999b.

DERTOUZOS, M. L. O que será: como o novo mundo da informação transformará nossas vidas. São Paulo: Companhia das Letras, 1998.

DRABENSTOTT, K. M.; BURMAN, C. M. Revisão analítica da biblioteca do futuro. Ciência da Informação, Brasília, v. 26, n. 2, p. 180-194, maio/ago. 1997.

DEMAS, S. Collection development or the electronic library: a conceptual and organizational model. Library Hi Tech, v. 47, p. 71-80, 1994.

FOSKETT, J. D. Pathways for communication: books and libraries in the information age. London: Clive Bingley, 1984.

GARCEZ, E. M. S.; RADOS, G. J. V. Biblioteca híbrida: um novo enfoque no suporte à educação a distância. Ciência da Informação, Brasília, v. 31, n. 2, p. 44-51, maio/ago. 2002.

GLADNEY, H. M. et al. Digital library: gross structure and requirements: report from a March 1994 Workshop, San Antonio, mar. 1994. Disponível em: <http://www.csdl.tamu.edu/DL94/paper/fox.html>. Acesso em: 20 fev. 2004.

GUSMÃO, A. O. M. Avaliação da qualidade e determinantes de desempenho do Aleph500 em bibliotecas universitárias brasileiras. 2001. 211 f. Dissertação (Mestrado em Ciência da Informação) - Centro de Ciências Sociais e Aplicadas, Universidade Federal da Paraíba, João Pessoa, 2001.

HOUAISS, A.; VILLAR, M. S. Dicionário Houaiss da Língua Portuguesa. Rio de Janeiro: Objetiva, 2001.

LANDONI, M. et al. Hyper-books and visual-books in an electronic library. The Electronic Library, v. 11, n. 3, p. 175-176, June, 1993. 
LANCASTER, F. W. Ameaça ou oportunidade?: o futuro dos servidores de biblioteca à luz das inovações tecnológicas. Revista da Escola de Biblioteconomia da Universidade Federal de Minas Gerais, Belo Horizonte, v. 23, n. 1, p. 7-27, jan./jun. 1994.

LANCASTER 1978 e 1982

LEVACOV, M. Bibliotecas virtuais: (r) evolução? Ciência da Informação, Brasília, v. 26, n. 2, p. 125-135, maio/ago. 1997.

MARCHIORI, P. Z. "Ciberteca” ou biblioteca virtual: uma perspectiva de gerenciamento de recursos de informação. Ciência da Informação, Brasília, v. 26, n. 2, p. 115-124, maio/ago. 1997.

MARTINS, R. D. Perspectiva para uma biblioteca no futuro: utopia ou realidade. Revista Informativa On-line, p. 1-15, 17 set. 2003. Disponível em: <http://biblioteca.estacio.br/artigos/005.htm>. Acesso em: 24 jan. 2005.

MARTINELLI, A. T. S. A A base de dados bibliográficos de acervo como suporte para o processo de automação: uma experiência na UNESP. In: SEMINÁRIO NACIONAL DE BIBLIOTECAS UNIVERSITÁRIAS, 10., 1998, Fortaleza. Anais eletrônicos. File:///cjnetscape/anais/trabalho/paineis/umaalter.htm

MCGARRY, K. O contexto dinâmico da informação: uma análise introdutória. Brasília: Briquet de Lemos, 1999.

MORIGI, V. J.; PAVAN, C. Tecnologias de informação e comunicação: novas sociabilidades nas bibliotecas universitárias. Ciência da Informação, Brasília, v. 33, n. 1, p. 117-125, jan./abr. 2004.

OHIRA, M. L. B.; PRADO, N. S. Bibliotecas virtuais e digitais: análise de artigos de periódicos brasileiros (1995-2000). Ciência da Informação, Brasília, v. 31, n. 1, p. 6174, jan./abr. 2002.

OPPENHEIM, C. Editorial. International Journal of Electronic Library Research, v. 1, n. 1, p. 1-2, 1997.

ORTIGARI, A. Verso la biblioteca digitale. Bibliotime, Bologna, nov. 1999. Disponível em: <http://www.spbo.unibo.it/bibliotime/num-ii-3/ortigari.htm>. Acesso em: $20 \mathrm{fev}$. 2004.

PEREIRA, M. N. F. Bibliotecas virtuais: realidade, possibilidade ou alvo de sonho. Ciência da Informação, Brasília, v. 24, n. 1, p. 1-15, jan./abr. 1995. Disponível em: $<$ http://www.ibict.br/cionline/include/getdoc.php?id=937\&article=583\&mode=pdf $>$. Acesso em: 28 jul. 2006.

PEREIRA, E. C.; RUTINA, R. O século XXI e o sonho da biblioteca universal: quase seis mil anos de evolução na produção, registro e socialização do conhecimento. Perspectivas Ciência da Informação, Belo Horizonte, v. 4, n. 1, p. 5-19, jan./jun. 1999. 
PENNIMAN, W. D. Shapping the future for library through leadership and research. In: LANCASTER, F. W. (Ed.). Library and the future: essays on the library in the twentyfirst century. New York: Haworth Press, 1993.

PIGGOTT, S. E. A. The virtual library almost there. Special Libraries, v. 84, n. 4, p. 206, Fall 1993.

POULTER, A. Building a browsable virtual reality library. Aslib Proceedings, v. 46, n. 6, p. 151, June 1994.

POWELL, A. Management models and measurement in thevirtual library. Special Libraries, v. 85, n. 4, p. 260, Fall 1994.

PROCÓPIO, E. Construindo uma biblioteca digital. São Paulo: Edições Inteligentes, 2005.

ROWLEY, J. A biblioteca eletrônica. Brasília: Briquet de Lemos, 2002.

ROOKS, D. The virtual library: pitfalls, promises and potentials. The Public Access Computer Systems Review, v. 4, n. 5, p. 22-29, 1993.

RUSCH-FEJA, D. Digital libraries: informatioform de zunkunft fur die informationsversorgung und informationsbereitstellung Disponível em: $<$ http://www.b-i-t-online.de/archiv/1999-02/fachbeit/rushfeja/artikel.htm>. Acesso em: 19 jun. 2000.

RUSBRIDGE, C. Towards the hybrid library. D-Lib Magazine, Jul./Ago. 1998.

SABATTINI, R. Bibliotecas digitais. Disponível em: <http://www.epub.org.br/correio/cp990605.htm>. Acesso em: 26 out. 1999.

SANTORO, M. Futuro delle memorie digitali e patrimonio culturale. Bibliotime, Bologna, nov. 2003. Disponível em: <http://www.spbo.unibo.it/bibliotime/num-vi3/santoro.htm>. Acesso em: 20 fev. 2004.

SALARELLI, A.; TAMMARO, A. M. La biblioteca digitale. Biblioteche oggi, Milano, jun. 2000. Disponível em: <http://www.bibliotecheoggi.it/2001/20010507601.pdf>. Acesso em: 20 fev. 2004.

SAUNDERS, L. M. Transforming acquisitions to support virtual libraries. Information Technology and Libraries, v. 14, n. 1, p. 42, March 1995.

SHARON, T.; FRANK, A. J. Bibliotecas digitales en Internet. 66th IFLA Council and General Conference. $\quad$ Israel: 2000. Disponível em: <http://www.ifla.org/IV/ifla66/papers/029-142s.htm>; Acesso em: 03 nov. 2003.

TENNANT, R. Digital v. electronic v. virtual libraries. Última atualização em 1999. Disponível em: <http://sunsite.berkeley.edu/mydefinitions.html>. Acesso em: 02 out. 2003. 
TRIVINHO, E. Cibercultura, sociossemiose e morte: sobrevivência em tempos de terror dromocrático. Revista Fronteiras: estudos midiáticos, São Leopoldo, v. 5, n. 2, p. 97123, dez. 2003.

VIRILIO, P. O espaço crítico. Rio de Janeiro: Ed. 34, 1993.

YORK 2002.

ZAFALON, Z. R. A informação nos meios tecnológicos e mediáticos pode servir à democracia? In: FUJITA, M. S. L. et al. A dimensão social da biblioteca digital na organização e acesso ao conhecimento: aspectos teóricos e aplicados. São Paulo: BT/SIBi / IBICT, 2005, v. 1, p. 105-120.

ZANG, N. et al. Biblioteca virtual: conceitos, metodologia e implantação. Revista de Pesquisa e Pós-Graduação, Erechim, n. 1, p. 217-236, 2000.

\section{Zaira Regina Zafalon}

Graduação em Biblioteconomia e Documentação pela Escola de Biblioteconomia e Documentação de São Carlos (1993) e mestrado em Comunicação e Semiótica pela Pontifícia Universidade Católica de São Paulo (2006). Concluiu cursos Lato Sensu em Sistemas Automatizados de Informação em Ciência \& Tecnologia, em Administração e em Ensino Superior. zaira.zafalon@uol.com.br

Recebido em: 19/08/2007

Aceito para publicação em: jan/2008 